\title{
Thromboxane-mediated Hypertension and Vascular Leakage Evoked by Low Doses of Escherichia coli Hemolysin in Rabbit Lungs
}

\author{
Werner Seeger, Henrik Walter, Norbert Suttorp, M. Muhly, and Sucharit Bhakdi \\ Division of Clinical Pathophysiology and Experimental Medicine, Department of Internal Medicine and Medical Microbiology, \\ Justus-Liebig-University Giessen, D-63 Giessen, Federal Republic of Germany
}

\begin{abstract}
Escherichia coli hemolysin has been implicated as a pathogenicity factor in extraintestinal $E$. coli infections including sepsis. In the present study the effects of intravascular administration of hemolysin were investigated in isolated blood-free perfused rabbit lungs. Low concentrations of the toxin in the perfusate (0.05-5 hemolytic units/ml, corresponding to $\sim 5-500 \mathrm{ng} / \mathrm{ml}$ ), caused a dose- and time-dependent release of potassium, thromboxane $A_{2}$, and prostaglandin $I_{2}$, but not of lactate dehydrogenase, into the recirculating medium, as well as a dose-dependent liberation of the prostanoids into the bronchoalveolar space. These events were paralleled by a dose-dependent pulmonary hypertension, and studies with different inhibitors collectively indicated that the vasoconstrictor response was mediated predominantly by pulmonary thromboxane generation. In addition, $E$. coli hemolysin elicited a protracted, dose-dependent increase in the lung capillary filtration coefficient, which was independent of the prostanoidmediated pressor response and resulted in severe pulmonary edema formation. We conclude that $E$. coli hemolysin can elicit thromboxane-mediated pulmonary hypertension combined with severe vascular leakage in isolated lungs in the absence of circulating inflammatory cells and humoral mediator systems, mimicking the key events in the development of acute respiratory failure in states of septicemia.
\end{abstract}

\section{Introduction}

Bacterial sepsis is the most consistent factor associated with the development of the acute respiratory distress syndrome in adults, gram-negative aerobic rods currently representing the predominant infectious agents (1-5). Moreover, acute diffuse lung injury of different etiology is often complicated by nosocomial pneumonia $(6,7)$. In experimental models septic lung failure can be mimicked by the intravenous infusion of live bacteria, e.g., live Escherichia coli (8-11). The key pathogenetic events, including acute pulmonary hypertension, delayed increase in vascular permeability, formation of protein-rich edema, and subsequent severe disturbances of gas exchange, can also be evoked by the administration of lipopolysaccharide

This manuscript includes parts of the thesis of Dr. Walter.

Address reprint requests to Dr. Werner Seeger, Division of Clinical Pathophysiology and Experimental Medicine, Department of Internal Medicine, Klinikstrasse 36, D-63 Giessen, FRG.

Received for publication 27 October 1987 and in revised form 13 January 1989.

J. Clin. Invest.

(C) The American Society for Clinical Investigation, Inc. 0021-9738/89/07/0220/08 \$2.00

Volume 84, July 1989, 220-227
(LPS) components of gram-negative bacteria (endotoxins) in intact animals, and detailed information is available on the mechanisms of lung injury by these agents. There is evidence for a critical role of circulating inflammatory cells, and activation of several humoral mediator systems (complement- and AA-cascade, reactive oxygen species, and proteases) has been documented (for review see references 12-16). In contrast to endotoxins, bacterial exotoxins have received little attention as possible instigators of pulmonary dysfunction. A study on the action of $E$. coli hemolysin appeared especially warranted since many lines of evidence implicate this toxin as an important factor of bacterial pathogenecity in extraintestinal $E$. coli infections. Whereas hemolysin-producing strains are infrequently encountered in the normal fecal flora, $\sim 50 \%$ of $E$. coli strains causing pyelonephritis and septicemia in humans are toxin producers, and hemolysin-producing strains also display enhanced virulence compared with isogenic nonproducers in various animal model infections (17-26). The toxin is secreted as a single chain polypeptide of $M_{\mathrm{r}} 107,000(27-29)$. Studies in erythrocytes and planar lipid membranes have shown that the hemolysin damages the cell membranes by insertion into the lipid bilayer and generation of a discrete, hydrophilic transmembrane pore with an effective diameter of $\sim 2 \mathrm{~nm}(30,31)$. E. coli hemolysin was recently identified as a potent leucocidin (32) and reported to induce chemoluminescence response as well as enzyme and leukotriene release from human neutrophils in vitro (33). In the present study we found that low doses of $E$. coli hemolysin are capable of mimicking key events of acute respiratory failure in blood-free perfuised lungs, in particular TX-mediated pulmonary hypertension and vascular leakage. $E$. coli hemolysin may thus directly contribute to the pathogenesis of respiratory failure in states of septicemia or pneumonial infections with hemolysin-producing strains of this gram-negative rod.

\section{Methods}

Isolated lung protocol. The model of isolated rabbit lungs, originating from animals with a body weight between 2.2 and $2.8 \mathrm{~kg}$, has been previously described (34-36). Briefly, the lungs were ventilated with $4 \% \mathrm{CO}_{2}, 17 \% \mathrm{O}_{2}$, and $79 \% \mathrm{~N}_{2}$ (frequency, 45 strokes/min; tidal volume, $30 \mathrm{ml}$ ), and the endexpiratory pressure was set zero. They were perfused with Krebs Henseleit buffer in a recirculating system (circulating volume, $180 \mathrm{ml}$ ) with a pulsatile flow of $100 \mathrm{ml} / \mathrm{min}$ at $37^{\circ} \mathrm{C}$. In the standard protocol, the buffer contained $1 \mathrm{~g} \% \mathrm{wt} / \mathrm{vol}$ bovine albumin. The alternate use of two perfusion systems allowed repeated exchanges of the perfusate by fresh buffer fluid. The left atrial pressure was set $2 \mathrm{mmHg}$ under baseline conditions ( 0 referenced at the hilum) to guarantee zone III conditions at endexpiration throughout the lung. Pulmonary artery pressure (PAP), ${ }^{1}$ pulmonary venous pressure (PVP;

1. Abbreviations used in this paper: $\mathrm{HU}$, hemolytic units; $K_{\mathrm{f}, \mathrm{c}}$, capillary filtration coefficient; KHAB, Krebs Henseleit albumin buffer; PAP, pulmonary artery pressure; PVP, pulmonary venous pressure. 
measured in the left atrium), peak inflation pressure, and the weight of the isolated organ were registered continuously. Only those lungs were selected for the study that $(a)$ displayed a homogenous white appearance without signs of hemostasis or edema formation, $(b)$ showed no spontaneous alteration of PAP or inflation pressure, and $(c)$ were completely isogravimetric during a steady-state period of at least $45 \mathrm{~min}$, during which the perfusion fluid was repeatedly exchanged. At the end of the steady-state period, remaining blood cells in the lung effluent ranged below $20 / \mu \mathrm{l}$ in all experiments. Random light microscopical examination of these lungs revealed virtually no erythrocytes or platelets, and few leukocytes in the vascular bed, and there was no evidence of interstitial edema or alveolar flooding. The wet to dry ratio of these lungs, corrected for the residual vascular volume, is known to lie in the physiological range (36). E. coli hemolysin was admixed to the perfusion fluid before recirculation after termination of the steady-state period. The experiments were terminated $60 \mathrm{~min}$ after administration of the hemolysin, or when a hemolysin-induced lung weight gain exceeded $20 \mathrm{~g}$ total. Inhibitors of AA metabolism were dissolved in 100-200 $\mu \mathrm{l}$ saline or ethanol and were also admixed to the buffer fluid before recirculation. The vehicles themselves are known to be ineffective in the small amounts used.

Capillary filtration coefficient $\left(K_{f, c}\right)$, vascular compliance, and bronchoalveolar lavage. $K_{\mathrm{f}, \mathrm{c}}$ was determined from the slope of weight gain, induced by a $7.5-\mathrm{mmHg}$ step elevation of the venous pressure for $8 \mathrm{~min}$. The application of this method to the present model has recently been described $(36,37)$, and the time schedule is shown in Fig. 9 . Zero time extrapolation of the slope of weight gain, using a semilogarithmic plot of $\Delta \mathrm{W} / \Delta \mathrm{t}$, was performed according to Taylor and Gaar (38). $K_{\mathrm{f}, \mathrm{c}}$ was calculated in terms of the elevation in venous pressure and expressed in cubic centimeters/millimeter $\mathrm{Hg}$ per gram wet lung weight per $s \times 10^{-4}$. The total vascular compliance, i.e., the change in the vascular volume per change in microvascular pressure, was determined from the initial rapid gain in lung weight after onset of the hydrostatic challenge (36) and is also given in terms of the venous pressure elevation (milliliters/millimeter $\mathrm{Hg}$ ). A bronchoalveolar lavage of the entire lung with $30 \mathrm{ml}$ saline total was performed at the end of the experiments as described (39).

Detection of prostanoids. TXA ${ }_{2}$ and $\mathbf{P G I}_{2}$ were assayed by RIA from the recirculating buffer fluid and the bronchoalveolar lavage fluid as their stable hydrolysis products $\mathrm{TXB}_{2}$ and 6-keto-PGF ${ }_{1}$ alpha as described $(34,40)$. Lactatedehydrogenase and potassium in the perfusion fluid were measured according to standard techniques.

Preparation of E. coli hemolysin. E. coli hemolysin was prepared by polyethylene glycol (PEG) precipitation of culture supernatant as described (30). The precipitated protein was dissolved in saline, aliquotted, and stored lyophilized at $-20^{\circ}$. The hemolytic titer was assessed directly before use and expressed in hemolytic units (HU)/milliliter (30). The hemolysin protein concentration was determined by an ELISA that uses a monoclonal anti-hemolysin antibody to capture the antigen, and a second, polyclonal rabbit antibody for development (40a). The assay was calibrated with a toxin standard obtained by incorporation of $E$. coli hemolysin into phosphatidylcholin liposomes and subsequent isolation of the liposomes by flotation in a sucrose density gradient. The protein content of this preparation was determined by quantitative amino acid analyses. A single polypeptide band of $M_{\mathrm{r}} 107,000$ was found upon SDS-PAGE. With this ELISA, it was found that a hemolytic titer of $1 \mathrm{HU} / \mathrm{ml}$ corresponded to a toxin protein concentration of $\sim 0.1 \mu \mathrm{g} / \mathrm{ml}$. Two control reagents were used. First, $E$. coli hemolysin preparations were allowed to age for several hours at $37^{\circ} \mathrm{C}$; this led to rapid loss of cytolytic activity (30), although the 107,000 protein band remained discernable in SDS-PAGE. Second, an isogenic $E$. coli strain lacking the hlyC gene was used. This strain produces and secretes a cytolytically inactive but antigenically identical 107,000 protein that is antigenically identical to the $E$. coli hemolysin used. The inactive protein was precipitated from culture supernatants, quantified by ELISA, and used in control experiments. The LPS content of hemolysin preparations was determined in several experiments. LPS was quantified with a chromogenic substrate using a commercially available test (41). The detection limit of the assay is 10 $\mathrm{pg} / \mathrm{ml}$. The LPS content of $E$. coli hemolysin preparations obtained after PEG precipitation was found to range between 60 and $150 \mathrm{ng} / \mu \mathrm{g}$ protein, or $\sim 10 \mathrm{ng} \mathrm{LPS/HU}$. This resulted in LPS concentrations of $\sim 50 \mathrm{ng} / \mathrm{ml}$ in the recirculating lung perfusate at the highest toxin doses applied ( $5 \mathrm{HU} / \mathrm{ml})$.

Four experiments were additionally conducted with toxin preparations that had been depleted of LPS. The method used for preparing this toxin was an extension and modification of a previously published procedure (42) and will be detailed elsewhere. In essence, PEG-precipitated toxin was dissolved in buffer and centrifuged twice over linear glycerol density gradients in a vertical rotor (type VTiG 5.1; Beckman Instruments, Inc., Palo Alto, CA). Each centrifugation was for 55 min at $220,000 \mathrm{~g}$ at $4^{\circ} \mathrm{C}$. The toxin was recovered in active and monomeric form from the second gradient. The final product contained $4-6 \mu \mathrm{g} / \mathrm{ml}$ protein and $12-18 \mathrm{ng} / \mathrm{ml}$ residual LPS (i.e., $\sim 3 \mathrm{ng} \mathrm{LPS} / \mu \mathrm{g}$ protein). These preparations were applied at final dilutions of 1:600, corresponding to hemolysin concentrations of $\sim 8-10 \mathrm{ng} / \mathrm{ml}$ or $0.2 \mathrm{HU} / \mathrm{ml}$ (after gradient centrifugation the toxin exhibited slightly higher specific activity compared with the original PEG-precipitated toxin). The resulting LPS concentrations in the lung perfusate were then 20-30 $\mathrm{pg} / \mathrm{ml}$; these values were confirmed by endotoxin assays of the perfusate.
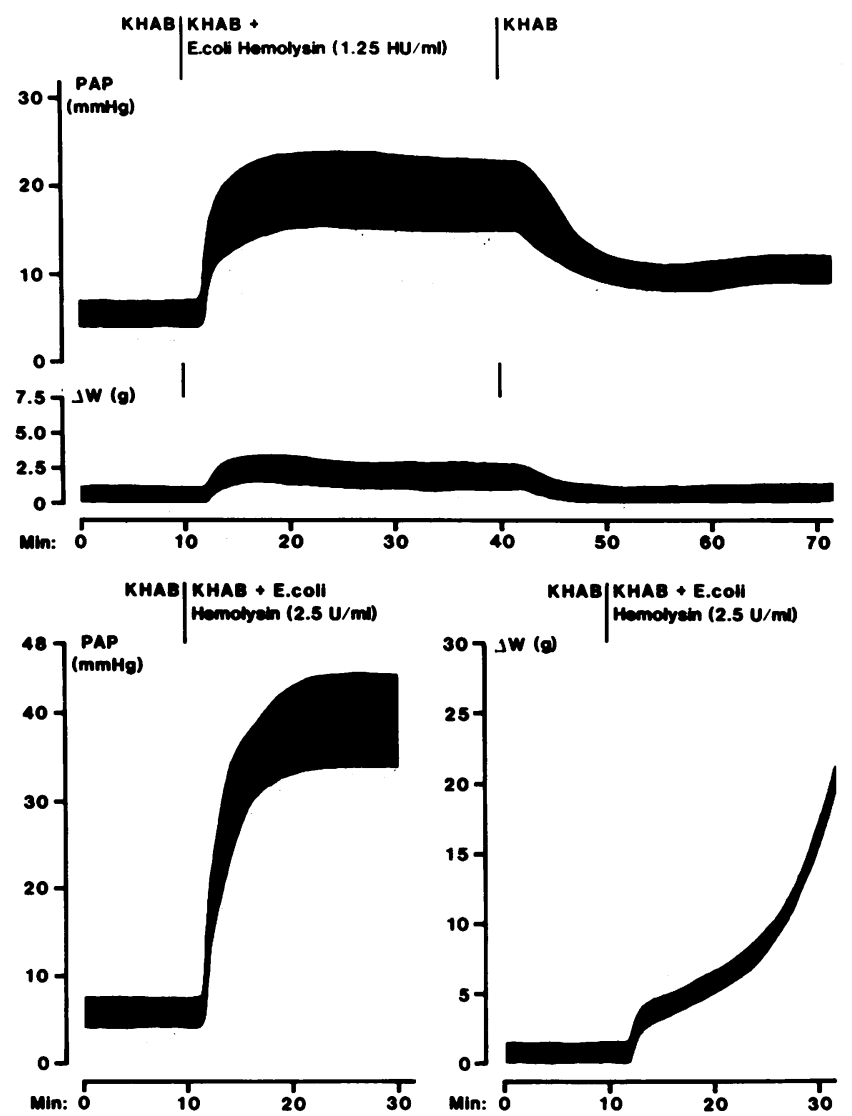

Figure 1. PAP and lung weight gain $(\Delta W)$ in two lungs exposed to 1.25 and $2.5 \mathrm{HU} / \mathrm{ml} E$. coli hemolysin. The lungs were perfused with Krebs Henseleit albumin buffer $(K H A B)$. Exchanges of the perfusion fluid are indicated by vertical lines. $E$. coli hemolysin was admixed to the buffer fluid at the given final concentrations before recirculation. Whereas $1.25 \mathrm{U}$ hemolysin/ml provoked a pressor response that was partly reversible upon change to toxin-free buffer and was not accompanied by a sustained increase in lung weight, the pulmonary hypertension evoked by $2.5 \mathrm{U}$ hemolysin/ $\mathrm{ml}$ was followed by a marked weight gain and the experiment was terminated after $30 \mathrm{~min}$. 
Reagents. Indomethacin was a gift from E. Merck (Darmstadt, FRG), BM 13.177 from Boehringer Mannheim GmbH (Mannheim, FRG), and OKY-046 from Ono Pharmaceutical Co. Ltd. (Osaka, Japan). D,L-Lysin-mono-acetylsalicylate/glycin (9:1) was obtained from Bayer AG (Leverkusen, FRG). Bovine albumin ( $96 \%$ purity, reduced in FFA to $<5 \mu \mathrm{g} / \mathrm{g}$ ), rabbit anti-6-keto-PGF ${ }_{1}$ alpha, and rabbit anti-TXB ${ }_{2}$ were received from Paesel AG (Frankfurt, FRG). Tritiumlabeled $\mathrm{TXB}_{2}$ and 6-keto-PGF 1 alpha were from New England Nuclear (Dreieich, FRG). A photometric test for the detection of LPS was obtained from Kabi Vitrum (Coatest endotoxin; Munich, FRG).

All values are given as mean \pm SE. Data were analyzed by one-way analysis of variance.

\section{Results}

E. coli hemolysin provoked an acute rise in PAP, plateauing after 5-10 min (Fig. 1). The magnitude of the pressor response was strictly dose dependent on the hemolysin concentration in the recirculating buffer fluid (Fig. 2). When the buffer fluid was not exchanged, the hemolysin-induced pulmonary hypertension persisted for $>2 \mathrm{~h}$; however, it was partly reversible upon rinsing the lung with toxin-free perfusate (example in Fig. 1). The pressor responses evoked by hemolysin concentrations up to $1.25 \mathrm{HU} / \mathrm{ml}$ were not accompanied by sustained alterations in lung weight. By contrast, the dramatic rises in PAP induced by $2.5-5 \mathrm{HU} / \mathrm{ml}$ perfusate were followed by a delayed, severe increase in lung weight. $E$. coli hemolysin caused a release of potassium, but not of $\mathrm{LDH}$ ( $<10 \mathrm{U} /$ liter), into the recirculating perfusate. The potassium liberation plateaued after $30 \mathrm{~min}$ and was again strictly dependent on the hemolysin concentration (Figs. 2-4). When the buffer fluid was exchanged by hemolysin-free medium $30 \mathrm{~min}$ after toxin application, a partial reuptake of potassium by the lungs was observed, approximately $40-55 \%$ within $30 \mathrm{~min}$.

The hemolysin-induced pressor response was accompanied by a rapid and dose-dependent release of $\mathrm{TXB}_{2}$ and 6-keto$\mathrm{PGF}_{1 \text { alpha }}$ into the recirculating medium (Fig. 5) as well as into

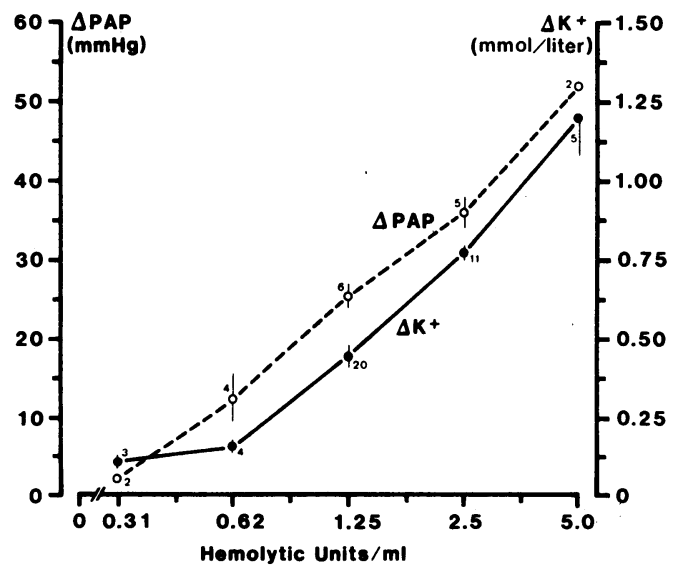

Figure 2. Dose dependence of pressor response and potassium release on the concentration of $E$. coli hemolysin in the perfusion fluid. The rise in mean PAP $(\triangle P A P)$ and the rise in potassium concentration in the recirculating $\mathrm{KHAB}(\Delta K) 30 \mathrm{~min}$ after administration of different concentrations of $E$. coli hemolysin are given. With respect to the potassium release, the data include experiments in which the pressure rise was suppressed by different inhibitors of the AA system (evaluation of the single data gave no difference in $\Delta K$ between lungs with or without such inhibitors). SE and the numbers of observation are indicated for each point.

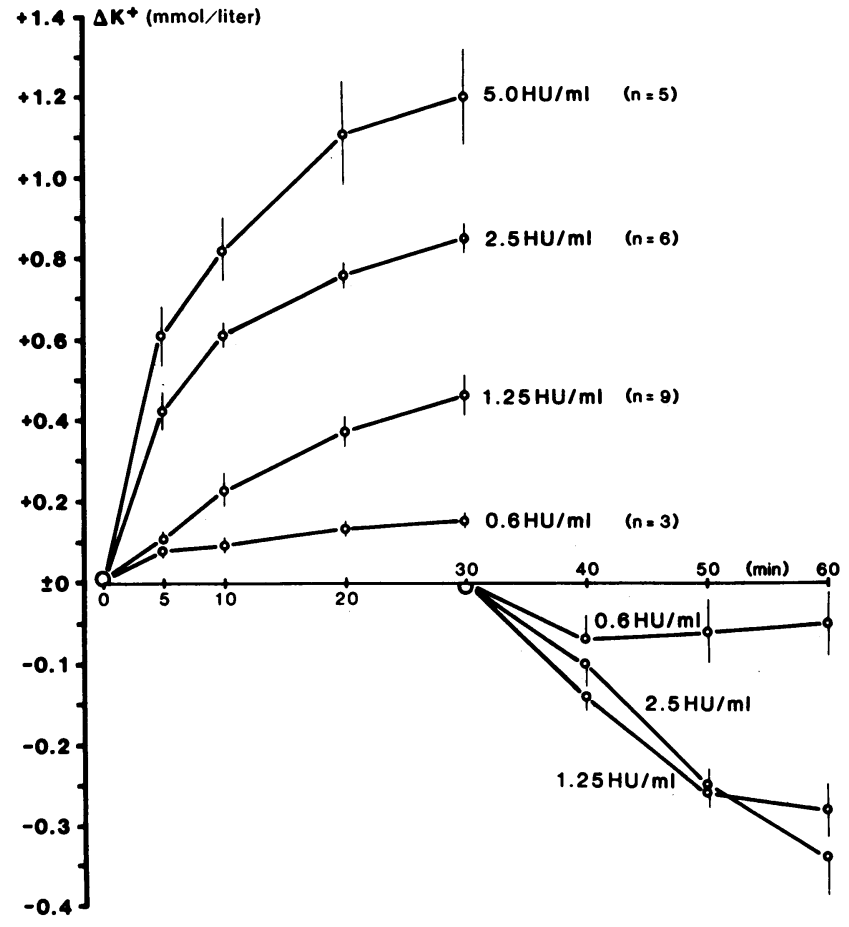

Figure 3. Dose dependence and time course of hemolysin-induced potassium release: partial reuptake after exchange of perfusion fluid. The Krebs Henseleit buffer fluid contained $5.2 \mathrm{mM}$ potassium before being recirculated. During a 30-min period of exposure of the lungs to $E$. coli hemolysin, a time- and dose-dependent increase of the potassium concentration in the buffer fluid was noted $(\Delta K)$. Next, the perfusate was exchanged by a toxin-free buffer fluid, again containing $5.2 \mathrm{mM}$ potassium. In the posttoxin phase, a decrease in the potassium concentration in the recirculating buffer fluid was noted, corresponding to a reuptake of this cation by the lung (note the different scale indicating $\Delta K$ ). This second (posttoxin) phase could not be performed in lungs exposed to $5 \mathrm{HU}$ hemolysin $/ \mathrm{ml}$ because of too rapid edema formation even in the presence of a cyclooxygenase inhibitor. In control lungs without toxin application, any changes in the perfusate potassium concentration ranged below $0.05 \mathrm{mM}$.

the bronchoalveolar space (Fig. 6). The cyclooxygenase inhibitors indomethacin and acetylsalicylic acid reduced both toxinevoked prostanoid generation and pressor response to a great extent (Fig. 7). In the presence of the TX synthase inhibitor OKY-046, both TX generation and pressure rise were blocked, whereas $\mathrm{PGI}_{2}$ liberation was unaffected. The TX receptor antagonist BM 13.177 inhibited the hemolysin-induced pressor response, but did not significantly influence the generation of both prostanoids. The slight depression of TX release in the presence of this specific receptor antagonist has already been observed in previous studies and may be explained by an interference with positive feedback mechanisms, i.e., interference with secondary AA metabolism and subsequent secondary TX formation by primarily induced TXA $\mathrm{TH}_{2}$ itself (43-45). None of the four inhibitors of the AA system affected the hemolysininduced release of potassium.

Both prostanoid generation and pressor response noted after administration of $E$. coli hemolysin were strictly dependent on extracellular calcium. When this bivalent cation was omitted from the buffer fluid and EGTA was additionally admixed to the perfusate, $E$. coli hemolysin still evoked potassium release to an undiminished extent; however, pressor re- 


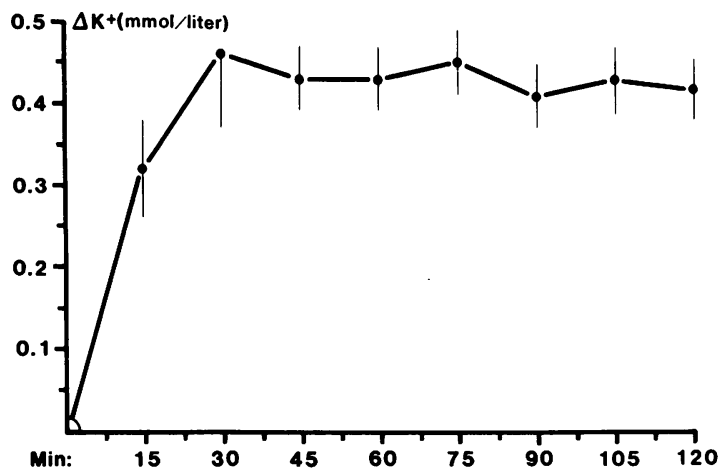

Figure 4. Time course of potassium release evoked by $1.25 \mathrm{HU} E$. coli hemolysin/ml perfusate: absence of perfusate exchange. The increase in the potassium concentration in the recirculating buffer fluid of seven isolated lungs exposed to $1.25 \mathrm{U}$ hemolysin/ml is given. In these experiments the buffer fluid was not exchanged during the 2-h period.

sponse (example in Fig. 8) and prostanoid release were completely suppressed $\left(\mathrm{TXB}_{2}<50 \mathrm{pg} / \mathrm{ml}\right.$ and 6-keto-PGF $\mathrm{P}_{1}$ alpha $<100 \mathrm{pg} / \mathrm{ml}$ in all experiments; $n=5$ ). Changing the perfusion fluid to calcium-containing (EGTA-free) medium, without a second application of the toxin, evoked a steep pressure increase without latent period, paralleled by a rapid release of both prostanoids. $10 \mathrm{~min}$ after reoffering calcium to a lung pretreated with $1.25 \mathrm{U}$ hemolysin/ml, a pressure rise of $14.0 \pm 2.2 \mathrm{mmHg}$, a $\mathrm{TXB}_{2}$ concentration in the perfusate of $274 \pm 57 \mathrm{pg} / \mathrm{ml}$, and a $6-\mathrm{keto}^{-} \mathrm{PGF}_{1}$ alpha concentration of $489 \pm 177 \mathrm{pg} / \mathrm{ml}$ were noted ( $n=4$ each). These data correspond well to those measured $10 \mathrm{~min}$ after administration of $E$. coli hemolysin in the presence of a calcium-containing perfusate. The maneuver of perfusate change from a calcium-free to a calcium-bearing medium itself did not provoke any significant rise in PAP or prostanoid generation ( $n=4$ control lungs).

To differentiate between pressure-induced fluid filtration and increased microvascular permeability as possible causative factors of the edema formation after $>1.25 \mathrm{U}$ hemolysin $/ \mathrm{ml}$, we took advantage of the nearly complete inhibition of any pressure rise by indomethacin. Performed in the presence of this cyclooxygenase inhibitor, a sequence of three hydrostatic challenges revealed a delayed, dose-dependent increase in the capillary filtration coefficient to severalfold values (Fig. 9; Table I). Since the vascular compliance was not augmented by the toxin, the manifold rise in $K_{\mathrm{f}, \mathrm{c}}$ must be ascribed to a severe increase in hydraulic conductivity rather than to an increase in the capillary surface area. This vascular leakage induced by the hemolysin was not reversible upon rinsing the lungs with toxin-free buffer. At all doses used, $E$. coli hemolysin did not cause an increase in the peak inflation pressure of the isolated lungs. Only in the experiments with marked edema formation $(>10 \mathrm{~g})$ a subsequent moderate rise occurred that was not further evaluated.

In an additional set of experiments $E$. coli hemolysin was administered to lungs perfused with Krebs Henseleit buffer in the absence of albumin as oncotic agent. In these lungs, the same features of dose-dependent potassium release, pressor response, and delayed increase in microvascular permeability were evoked by toxin doses approximating $1 / 25$ of those used in the presence of albumin, i.e., by subhemolytic concentrations ranging between 0.05 and $0.2 \mathrm{HU} / \mathrm{ml}$ (Table II). In four isolated lungs perfused with Krebs Henseleit buffer in the presence of $100 \mu \mathrm{M}$ acetylsalicylic acid according to the protocol given in Table II, hemolysin preparations with markedly reduced LPS content ( $\sim 3 \mathrm{ng} / \mu$ g protein) were used to give a final hemolysin concentration of $10 \mathrm{ng} / \mathrm{ml}$, corresponding to $\sim 0.2 \mathrm{HU} / \mathrm{ml}$, in the lung perfusate. The LPS content in these experiments was determined to be $<10,20-30$, and 20-30 $\mathrm{pg} / \mathrm{ml}$ before, $5 \mathrm{~min}$ after, and $20 \mathrm{~min}$ after hemolysin application, respectively. The $K_{\mathrm{f}, \mathrm{c}}$ values of these lungs were $2.2 \pm 0.3$ before and > $1030 \mathrm{~min}$ after hemolysin application and were thus not different from those noted in the corresponding experiments with hemolysin not reduced in LPS (Table II). Additional control studies were performed using either aged, hemolytically inactive $E$. coli hemolysin preparations, or inactive 107,000 protein secreted by an isogenic $E$. coli strain lacking the hlyC gene. In both cases application of these preparations failed to elicit the described pressor response and vascular leakage $(n=3$ each).

\section{Discussion}

The present study shows that $E$. coli hemolysin can dose-dependently induce severe alterations in lung physiology in the

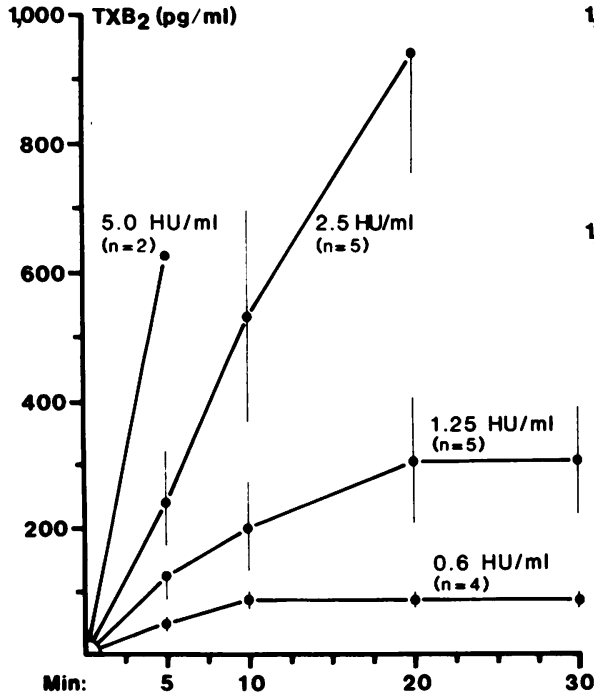

Figure 5. Dose dependence and time course of $E$. coli hemolysin-induced prostanoid release into the perfusion fluid. The figure gives the concentrations of $\mathrm{TXB}_{2}$ and 6-keto-PGF alpha $_{1}$, measured in aliquots of the recirculating buffer fluid at different times after administration of the various doses of the hemolysin. The experiments were performed in the absence of an AA cascade inhibitor. In the studies with application of 2.5 and $5 \mathrm{U}$ hemolysin/ml the experiments had to be stopped before termination of the 30-min period because of a total lung weight gain surpassing $20 \mathrm{~g}$. 


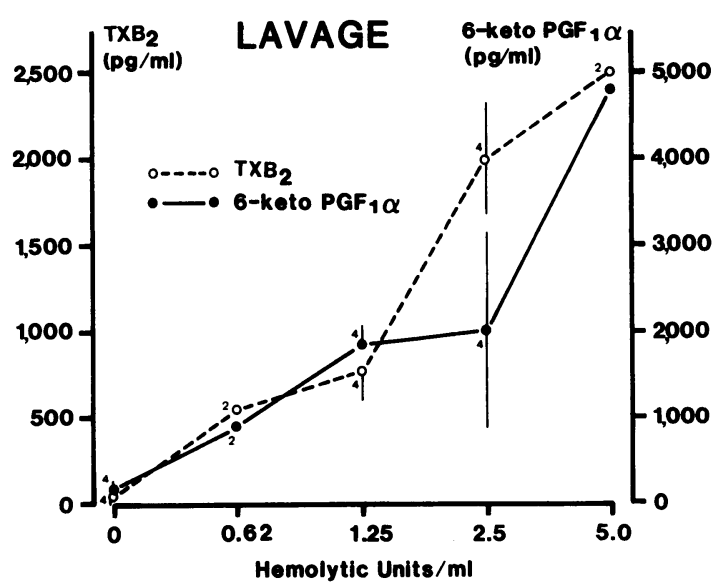

Figure 6. Dose dependence of $E$. coli hemolysin-induced prostanoid release into the bronchoalveolar space. The experiments correspond to those in Fig. 5. In studies with 0.6 and $1.25 \mathrm{HU} / \mathrm{ml}$, bronchoalveolar lavage was performed directly after the $30 \mathrm{~min}$ exposure to $E$. coli hemolysin. In experiments with 2.5 and $5 \mathrm{U} / \mathrm{ml}$, perfusion had to be stopped before termination of the $30-\mathrm{min}$ period because of a total lung weight surpassing $20 \mathrm{~g}$, resulting in incubation periods between 10 and $25 \mathrm{~min}$, and lavage was performed immediately thereafter. The numbers of lung experiments with the different hemolysin concentrations analyzed by lavage are indicated in the figure. Prostanoids are given in picograms/milliliter lavage fluid. The low values of non-toxin-exposed control lungs correspond to those in a previous study in which $\mathrm{TXB}_{2}$ and 6-keto-PGF $\mathrm{Palpha}_{1}$ were found to range below 100 and $200 \mathrm{pg} / \mathrm{ml}$ lavage fluid, respectively, under baseline conditions (39).

absence of plasma proteins and blood cells. The noted acute rise in PAP and the delayed but severe increase in lung vascular permeability correspond to key events encountered in the early stages of septic lung failure, a variant of the acute respiratory distress syndrome of the adult. There is clear evidence that the observed pulmonary effects were elicited by the hemolysin and not by contaminating LPS. First, aging of toxin preparations at $37^{\circ} \mathrm{C}$ caused disappearance of hemolytic activity which was paralleled by loss of toxicity in the lung. Second, 107,000 protein preparations from an isogenic $E$. coli strain lacking cytolytic activity were also ineffective in the lung. Third, there was a clear dose-effect relationship between the hemolytic activity measured in vitro and the evoked changes in lung physiology, i.e., potassium release, prostanoid generation, pressor response, and microvascular leakage. Finally, the use of toxin preparations that had been markedly depleted of LPS still led to unrestricted physiological pulmonary responses. In these experiments the endotoxin content was so low that final concentrations in the perfusate ranged between 20 and $30 \mathrm{pg} / \mathrm{ml}$. Under no circumstances have such low concentrations of LPS ever been reported to evoke acute pulmonary reactions. Indeed, it is known from previous studies that even far larger amounts of endotoxin $(>1 \mu \mathrm{g} / \mathrm{ml})$ do not provoke acute alterations in lung physiology or prostanoid generation in blood-free perfused isolated lungs (46-48; Seeger, W., unpublished data).

The hemolysin-induced pressor response is a primary event and not secondary to lung edema formation. At toxin concentrations below $1.25 \mathrm{U} / \mathrm{ml}$ pulmonary hypertension occurred without any significant gain in lung weight, and at higher toxin doses the rise in PAP clearly preceded the edema formation. Moreover, several recent studies have demonstrated that even large amounts of lung edema do not necessarily affect pulmonary vascular resistance (49-51).

Pulmonary TX generation appears to be predominantly responsible for the toxin-induced vasoconstrictor response. There was a dose-effect relationship between applied toxin levels and concentrations of $\mathrm{TXB}_{2}$ in the recirculating medium and in the bronchoalveolar lavage fluid. Inhibitors of cyclooxygenase and TX synthase, as well as a TX receptor antagonist all significantly blocked the pressure rise. Furthermore, application of the stable TX analogue U-46619 provokes pressor responses in concentrations comparable to the $\mathrm{TXB}_{2}$ levels measured in the present study. The vasoconstrictive potency of TX evidently surpasses the vasodilatory effect of $\mathrm{PGI}_{2}$, which was co-released in comparable concentrations into the vascular and the alveolar compartment. The same finding has been made with a variety of other stimulatory agents in the rabbit lung model (52).

The time course and magnitude of the hemolysin-induced pressor response were reminiscent of the acute pulmonary hypertension induced by Staphylococcus aureus alpha toxin (34). The latter generates transmembrane pores of similar dimensions to those produced by $E$. coli $(53,54)$. Studies in the rabbit lung (34), cultured pulmonary artery endothelial cells (55), and granulocytes (56) collectively suggested that the toxin-cre-
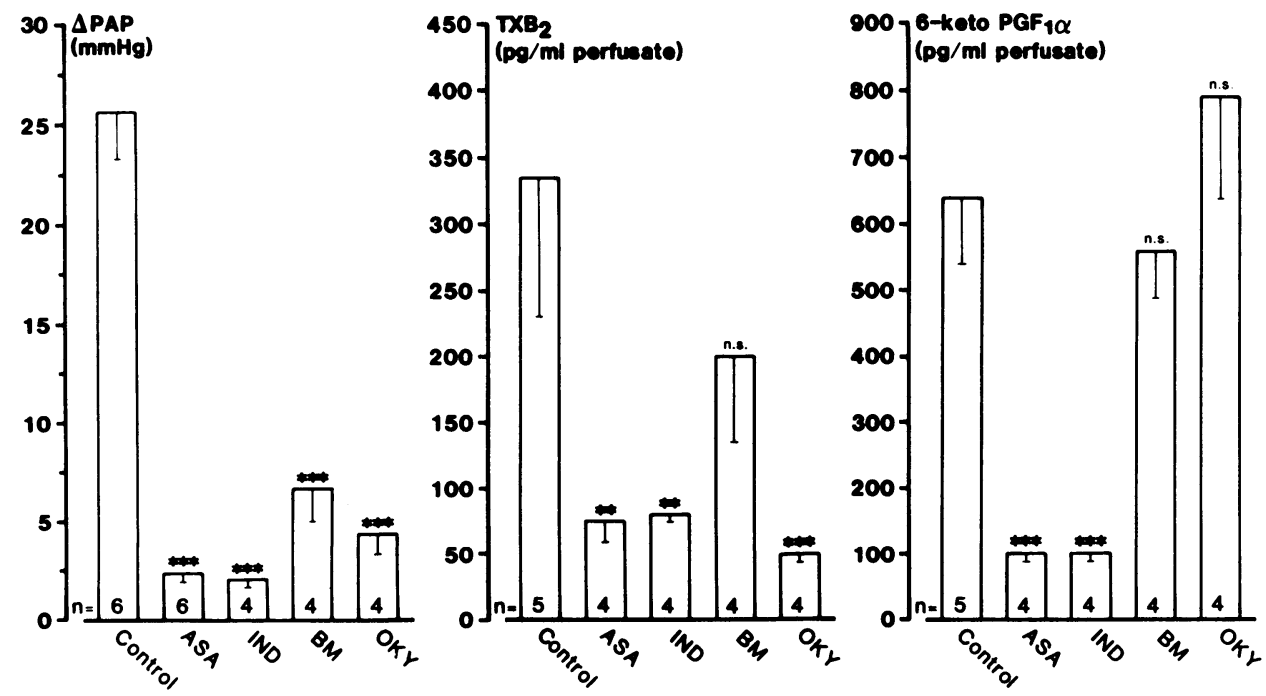

Figure 7. Influence of different AA cascade inhibitors on $E$. coli hemolysin-induced prostanoid generation and pressor response. The lungs were exposed to $1.25 \mathrm{HU}$ hemoly$\mathrm{sin} / \mathrm{ml}$ perfusate in the absence (control) or presence of different inhibitors of the lung AA system. The maximum values of PAP rise $(\triangle P A P)$ as well as $\mathrm{TXB}_{2}$ and 6-keto$\mathrm{PGF}_{1 \text { alpha }}$ concentrations in the perfusion fluid are given. The values of the different inhibitor groups are compared with the control group by one-way analysis of variance. ${ }^{* *} P$ $<0.01,{ }^{* * *} P<0.001$. ASA, acetylsalicylic acid, $100 \mu \mathrm{M} ; I N D$, indomethacin, $35 \mu \mathrm{M} ; B M$, BM 13.177, $10 \mu \mathrm{M} ; O K Y$, OKY-046, $2.5 \mu \mathrm{M}$. 

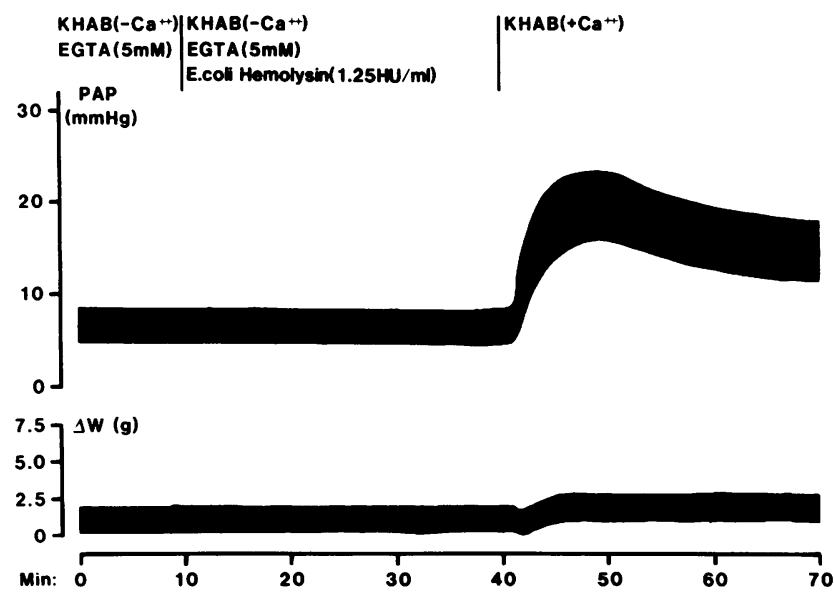

Figure 8. Influence of extracellular calcium on $E$. coli hemolysin-induced pressor response. The lung was perfused with calcium-free KHAB containing $5 \mathrm{mM}$ EGTA. Under these conditions, $1.25 \mathrm{HU}$ hemolysin/ml perfusate evoked no pressor response (and no prostanoid release; data not given). Change of the perfusate to EGTA-free calcium-bearing buffer (vertical line) without a second toxin application evoked a rapid pressor response.

ated pores probably serve as nonphysiological calcium bypass gates, triggering cell-specific AA metabolism at concentrations that are below the threshold of overt cell damage (52). Ion
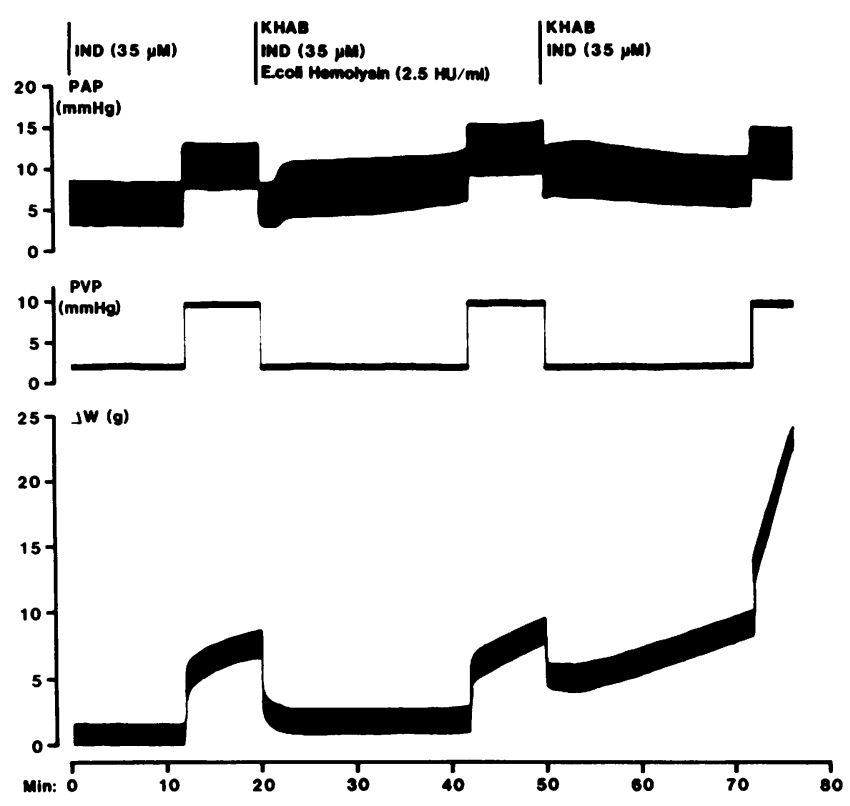

Figure 9. Lung weight gain induced by $E$. coli hemolysin in the presence of a cyclooxygenase inhibitor. The figure gives the PAP, the PVP, and lung weight gain $(\Delta W)$; the vertical lines indicate changes of perfusion fluid. The lung was perfused with $\mathrm{KHAB}$, with indomethacin (IND) being admixed to the perfusate in each perfusion phase. A sequence of three PVP challenges was induced. Each of these maneuvers caused an instantaneous rise in PAP, an immediate rise in lung weight (assumed to represent mainly filling of the vascular compartment), and a slower phase of weight gain (assumed to represent mainly fluid filtration), from which the capillary filtration coefficient is calculated. In the presence of the cyclooxygenase inhibitor indomethacin, $E$. coli hemolysin caused only a very moderate increase in PAP; however, the venous challenge $22 \mathrm{~min}$ and in particular $52 \mathrm{~min}$ after toxin application demasked a severalfold increase in the venous challenge-induced fluid filtration.
Table I. $K_{f, c}$ and Vascular Compliance after the Application of $E$. coli Hemolysin in the Presence of Cyclooxygenase Inhibition

\begin{tabular}{lccc}
\hline \multicolumn{1}{c}{ Hemolysin dose } & First challenge & Second challenge & Third challenge \\
\hline Control $(n=7)$ & & & \\
$\mathrm{K}_{\mathrm{f,c}}$ & $1.67 \pm 0.23$ & $1.78 \pm 0.14$ & $1.85 \pm 0.20$ \\
Compliance & $0.52 \pm 0.03$ & $0.50 \pm 0.03$ & $0.58 \pm 0.04$ \\
$\Delta \mathrm{W}$ & $0.9 \pm 0.4$ & $0.6 \pm 0.2$ & $1.9 \pm 0.8$ \\
$1.25 \mathrm{U} / \mathrm{ml}(n=10)$ & & & \\
$\mathrm{K}_{\mathrm{f,c}}$ & $1.58 \pm 0.13$ & $1.34 \pm 0.11$ & $1.91 \pm 0.25$ \\
Compliance & $0.47 \pm 0.02$ & $0.49 \pm 0.02$ & $0.52 \pm 0.03$ \\
$\Delta \mathrm{W}$ & $0.6 \pm 0.4$ & $0.5 \pm 0.2$ & $1.8 \pm 0.5$ \\
$2.5 \mathrm{U} / \mathrm{ml}(n=6)$ & & & \\
$\mathrm{K}_{\mathrm{f,c}}$ & $1.53 \pm 0.24$ & $1.12 \pm 0.07$ & $>10$ \\
Compliance & $0.45 \pm 0.04$ & $0.41 \pm 0.02$ & $0.44 \pm 0.04$ \\
$\Delta \mathrm{W}$ & $0.7 \pm 0.3$ & $2.3 \pm 0.3$ & $>10$ \\
$5 \mathrm{U} / \mathrm{ml}(n=5)$ & & & \\
$\mathrm{K}_{\mathrm{f,c}}$ & $1.67 \pm 0.07$ & $>10$ & \\
Compliance & $0.47 \pm 0.03$ & $0.47 \pm 0.04$ & \\
$\Delta \mathrm{W}$ & $0.7 \pm 0.2$ & $>10$ & \\
\end{tabular}

All lungs were perfused with KHAB. $35 \mu \mathrm{M}$ indomethacin was admixed to the perfusate in all perfusion phases. Three PVP challenges of $7.5 \mathrm{mmHg}$ were performed according to the time schedule in Fig. 9. For each group the capillary filtration coefficient $\left(\mathrm{K}_{\mathrm{f}, \mathrm{c}} ;\right.$ cubic centimeters/millimeter $\mathrm{Hg}$ per gram wet lung weight per $\left.\mathrm{s} \times 10^{-4}\right)$, the vascular compliance (milliliters/millimeter $\mathrm{Hg}$ ) and the net weight gain between onset and termination of each venous pressure elevation ( $\Delta \mathrm{W}$; grams) are given. The first hydrostatic challenge preceded hemolysin application, the second was performed $22 \mathrm{~min}$ and the third 52 min after administration of the toxin (due to massive edema formation a third hydrostatic challenge could not be performed in the lungs stimulated with $5 \mathrm{U}$ hemolysin/ml perfusate).

The baseline PAP (5-10 $\mathrm{mmHg}$ ) and the venous challenge-induced rise in PAP (3.5-4.5 $\mathrm{mmHg}$ ) did not differ between the different groups. Due to the presence of the cyclooxygenase inhibitor indomethacin, the hemolysin-induced PAP rise ranged below $3.5 \mathrm{mmHg}$ in all experiments.

fluxes through membranes treated with $E$. coli hemolysin have been demonstrated in erythrocytes (30) and planar lipid bilayers (31). The dose-dependent release of potassium, but not of lactatedehydrogenase, from lung cells observed in the present study is compatible with an analogous membrane perturbation mechanism in the rabbit lung. The strict dependence of prostanoid generation and pressor response (but not of the potassium release) on extracellular calcium suggests an analogous sequel of events to that found for the staphylococcal alpha toxin, i.e., transmembrane calcium flux and stimulation of arachidonate metabolism in the toxin-attacked cells, followed by TX-mediated vasoconstriction. The cellular origin of TX has not been established in the rabbit lung; endothelial cells are the most likely source of $\mathrm{PGI}_{2}(52)$. In contrast to the effects of the staphylococcal toxin, those of $E$. coli hemolysin appeared partially reversible. The elevated PAP was partially reduced upon rinsing of the lung vasculature with toxin-free buffer, and reuptake of potassium into the lung tissue was noted. At present no data are available on possible repair mechanisms for toxin lesions in nucleated cells.

Increase in lung vascular permeability represented a second event of prime pathophysiological importance elicited by $E$. coli hemolysin. The rise of $K_{\mathrm{f}, \mathrm{c}}$ occurred at toxin concentrations $>1.25 \mathrm{HU} / \mathrm{ml}$. Onset was delayed, but vascular leakage 
Table II. Potassium Release, Pressor Response, and Increase in Microvascular Permeability Induced by Subhemolytic Concentrations of E. coli Hemolysin in the Absence of Circulating Albumin

\begin{tabular}{|c|c|c|c|c|c|}
\hline \multirow[b]{2}{*}{ Hemolysin } & \multirow[b]{2}{*}{$\Delta \mathbf{K}^{*}$} & \multirow[b]{2}{*}{$\triangle \mathrm{PAP}^{\ddagger}$} & \multicolumn{3}{|c|}{$K_{f, c}{ }^{8}$} \\
\hline & & & First challenge & Second challenge & Third challenge \\
\hline & mmol/liter & $m m H g$ & \multicolumn{3}{|c|}{$\mathrm{cm}^{3} / \mathrm{mmHg}$ per $\mathrm{g}$ wet weight per $s \times 10^{-4}$} \\
\hline $0.05 \mathrm{U} / \mathrm{ml}$ & $0.51 \pm 0.05 ; n=5$ & $\begin{array}{c}10 \\
n=2\end{array}$ & $1.43 \pm 0.17 ; n=3$ & $2.36 \pm 0.19 ; n=3$ & $2.50 \pm 0.17 ; n=3$ \\
\hline $0.1 \mathrm{U} / \mathrm{ml}$ & $0.90 \pm 0.06 ; n=3$ & $\begin{array}{c}22 \\
n=2\end{array}$ & $2.0 \pm 0.5 ; n=3$ & $6.83 \pm 2.1 ; n=3$ & $\begin{array}{c}>10 \\
n=3\end{array}$ \\
\hline $0.2 \mathrm{U} / \mathrm{ml}$ & $1.20 \pm 0.04 ; n=5$ & $\begin{array}{c}39 \\
n=2\end{array}$ & $2.46 \pm 0.67 ; n=3$ & $\begin{array}{c}>10 \\
n=3\end{array}$ & \\
\hline
\end{tabular}

The lungs were perfused with Krebs Henseleit buffer without albumin, and the hemolysin was admixed to the perfusion fluid as described for the experiments in the presence of albumin. ${ }^{*} \Delta \mathrm{K}$ gives the increase in the potassium concentration in the recirculating perfusate measured 30 min after application of $E$. coli hemolysin at the given concentrations. ${ }^{\ddagger} \triangle \mathrm{PAP}$ gives the maximum rise in mean PAP after administration of the hemolysin at the given concentrations in the absence of cyclooxygenase inhibition. ${ }^{\S}$ The $K_{\mathrm{f}, \mathrm{c}}$ was determined from three venous pressure challenges as described in Table I. These studies were performed in the presence of $100 \mu \mathrm{M}$ acetylsalicylic acid, which suppressed the hemolysin-evoked pressure rise to $<3 \mathrm{mmHg}$ in all experiments. The ranges of baseline PAP, venous challenge-induced pressure rise, and vascular compliance did not differ among the given groups and did not differ from the data given in Table I for experiments in the presence of albumin.

then progressed unhaltingly and irreversibly, leading to pulmonary edema. This process was not dependent on lung prostanoid generation and pressure rise; the possible involvement of lipoxygenase metabolism of AA implicated in increased lung vascular permeability $(36,37,52)$, requires further investigation.

The concentrations of $E$. coli hemolysin required to evoke acute alterations in the lung vasculature are remarkably low: $1-5 \mathrm{HU} / \mathrm{ml}(100-500 \mathrm{ng} / \mathrm{ml})$ in the presence of circulating albumin, and $0.05-0.2 \mathrm{HU} / \mathrm{ml}(5-20 \mathrm{ng} / \mathrm{ml})$ in protein-free perfusion fluid. Levels of the hemolysin produced by the present $E$. coli strain reach $>100 \mathrm{HU} / \mathrm{ml}$ after $4 \mathrm{~h}$ of growth in culture (40a). Although wild strains are generally weaker toxin producers, it is conceivable that toxin levels sufficient to induce pulmonary dysfunction may be attained during in vivo infections. Moreover, it has to be emphasized that the alterations in lung physiology were induced in the absence of granulocytes and humoral effector systems such as the complement cascade. As $E$. coli hemolysin was reported to activate granulocytes $(32,33)$, the presence of these inflammatory cells may even amplify the detrimental effects of the toxin in the lung. $E$. coli hemolysin emerges as a potentially significant contributor to the pathogenesis of acute respiratory failure arising during severe infections with this important human pathogen.

\section{Acknowledgments}

We thank Ch. Ernst, H. Michnacs, G. Becker, and M. Pohl for excellent technical assistance, and P. Müller for skillful graphic illustration.

This study was supported by the Deutsche Forschungsgemeinschaft (Ne-195/4-3, SE-454/2-1, BH-2/2, and SFB-249) and the Verband der Chemischen Industrie.

\section{References}

1. Fowler, A. A., R. F. Hamman, G. O. Zerbe, K. N. Benson, and T. M. Hyers. 1985. Adult respiratory distress syndrome: prognosis after onset. Am. Rev. Respir. Dis. 132:472-478.

2. Montgomery, A. B., M. A. Stager, C. J. Carrico, and L. D.
Hudson. 1985. Causes of mortality in patients with adult respiratory distress syndrome. Am. Rev. Respir. Dis. 132:485-489.

3. Hyers, T. M., and A. A. Fowler. 1986. Adult respiratory distress syndrome: causes, morbidity, and mortality. Fed. Proc. 45:25-29.

4. Rinaldo, J. E., and R. M. Rogers. 1986. Adult respiratory distress syndrome. N. Engl. J. Med. 315:578-579.

5. Seidenfeld, J. J., D. F. Pohl, R. C. Bell, G. D. Harris, and W. G. Johanson, Jr. 1986. Incidence, site and outcome of infections in patients with the adult respiratory distress syndrome. Am. Rev. Respir. Dis. 134:12-16.

6. Andrews, C. P., J. J. Coalson, J. D. Smith, and W. G. Johanson. 1981. Diagnosis of nosocomial pneumonia in acute, diffuse lung injury. Chest. 80:254-258.

7. Bodey, G. P., L. Jadeja, and L. Elting. 1985. Pseudomonas bacteremia. Arch. Intern. Med. 145:1621-1629.

8. Brigham, K., C. Begley, and G. Bernard. 1983. Septicemia and lung injury. Clin. Lab. Med. 3:719-744.

9. Smith, L., S. Andreasson, K. Thoren-Tolling, and B. Risberg. 1986. The pulmonary microvascular response to infusion of live Escherichia coli in sheep with acutely or chronically prepared lung lymph fistula. Circ. Shock. 19:409-422.

10. Taylor, F. B., Jr., A. Chang, C. T. Esmon, A. D'Angelo, and K. E. Blick. 1987. Protein C prevents the coagulopathic and lethal effects of Escherichia coli infusion in the baboon. J. Clin. Invest. 79:918-925.

11. Dobkin, E. D., T. E. Lobe, J. Bhatia, K. T. Oldham, and D. L. Traber. 1985. The study of fecal-Escherichia coli peritonitis-induced septic shock in a neonatal pig model. Circ. Shock. 16:325-336.

12. Repine, J. E., and R. M. Tate. 1983. Oxygen radicals and lung edema. Physiologist. 26:171-181.

13. Brigham, K. L., and B. Meyrick. 1984. Interactions of granulocytes with the lungs. Circ. Res. 54:623-634.

14. Traber, D. L. 1985. Pulmonary microvascular dysfunction during shock. In Circulatory Shock: Basic and Clinical Implications. H. F. Janssen and G. D. Barnes, editors. Academic Press, New York. 23-46.

15. Malik, A. B., M. B. Perlan, J. A. Cooper, T. Noonan, and R. Bizios. 1985. Pulmonary microvascular effects of arachidonic acid metabolites and their role in lung vascular injury. Fed. Proc. 44:36-42.

16. Brigham, K. L., and B. Meyrick. 1986. State of art: endotoxin and lung injury. Am. Rev. Respir. Dis. 133:913-927.

17. Fried, F. A., C. W. Vermeulen, M. J. Ginsberg, and C. M. Cone. 1971. Etiology of pyelonephritis: further evidence associating the pro- 
duction of experimental pyelonephritis with hemolysis in Escherichia coli. J. Urol. 106:351-354.

18. Welch, R. A., E. P. Dellinger, B. Minshew, and S. Falkow. 1981. Haemolysin contributes to virulence of extra-intestinal $E$. coli infections. Nature (Lond.). 294:665-667.

19. van den Bosch, J. F., L. Emody, and I. Keteyi. 1982. Virulence of haemolytic strains of Escherichia coli in various animal models. FEMS (Fed. Eur. Microbiol. Soc.) Microbiol. Lett. 13:427-430.

20. van den Bosch, J. F., P. Postma, P. A. R. Koopman, J. de Graaf, C. M. MacLaren, D. G. Brenk, and P. A. M. Guinee. 1982. Virulence of urinary and faecal Escherichia coli in relation to serotype, haemolysis and haemagglutination. J. Hyg. 88:567-577.

21. Waalwijk, C., D. M. MacLaren, and J. de Graaf. 1983. In vivo function of hemolysin in the nephropathogenicity of Escherichia coli. Infect. Immun. 42:245-249.

22. Hacker, J., C. Hughes, H. Hof, and W. Goebel. 1983. Cloned hemolysin genes from Escherichia coli that cause urinary tract infection determine different levels of toxicity in mice. Infect. Immun. 42:57-63.

23. Hughes, C., J. Hacker, A. Robert, and W. Goebel. 1983. Hemolysin production as a virulence marker in symptomatic and asymptomatic urinary tract infections caused by Escherichia coli. Infect. Immun. 39:546-551.

24. Cavalieri, S. J., G. A. Bohach, and I. S. Snyder. 1984. Escherichia coli alpha-hemolysin: characteristics and probable role in pathogenicity. Microbiol. Rev. 48:326-343.

25. Welch, R. A., and S. Falkow. 1984. Characterization of Escherichia coli hemolysin conferring quantitative differences in virulence. Infect. Immun. 43:156-160.

26. Fünfstück, R., H. Tschäpe, G. Stein, H. Kunath, M. Bergner, and G. Wessel. 1986. Virulence properties of Escherichia coli strains in patients with chronic pyelonephritis. Infection. 14:145-150.

27. Mackman, N., and I. B. Holland. 1984. Secretion of a $107 \mathrm{~K}$ dalton polypeptide into the medium from a haemolytic $E$. coli $\mathrm{K} 12$ strain. Mol. \& Gen. Genet. 193:312-315.

28. Gonzalez-Carrero, M. I., J. C. Zabala, F. de la Cruz, and J. M. Oritz. 1985. Purification of alpha-haemolysin from an overproducing E. coli strain. Mol. \& Gen. Genet. 199:106-110.

29. Felmlee, T., S. Pellet, E. Y. Lee, and R. Welch. 1985. Nucleotide sequence of an Escherichia coli chromosomal hemolysin. J. Bacteriol. 163:94-105.

30. Bhakdi, S., N. Mackman, J.-M. Nicaud, and I. B. Holland. 1986. Escherichia coli hemolysin may damage target cell membranes by generating transmembrane pores. Infect. Immun. 52:63-69.

31. Menestrina, G., N. Mackman, I. B. Holland, and S. Bhakdi. 1987. E. coli hemolysin forms voltage-dependent ion channels in lipid membranes. Biochim. Biophys. Acta. 905:109-117.

32. Bhakdi, S., S. Greulich, M. Muhly, B. Eberspächer, H. Becker, A. Thiele, and F. Hugo. 1989. Potent leucocidal action of Escherichia coli hemolysin mediated by permeabilization of target cell membranes. J. Exp. Med. 169:737-754.

33. König, B., W. König, J. Scheffer, J. Hacker, and W. Goebel. 1986. Role of Escherichia coli alpha-hemolysin and bacterial adherence in infection: requirement for release of inflammatory mediators from granulocytes and mast cells. Infect. Immun. 54:886-892.

34. Seeger, W., M. Bauer, and S. Bhakdi. 1984. Staphylococcal alpha-toxin elicits hypertension in isolated rabbit lungs. Evidence for thromboxane formation and the role of extracellular calcium. J. Clin. Invest. 74:849-858.

35. Seeger, W., G. Stöhr, H. R. D. Wolf, and H. Neuhof. 1985. Alteration of surfactant function due to protein leakage: special interaction with fibrin monomer. J. Appl. Physiol. 587:326-338.

36. Seeger, W., D. Walmrath, M. Menger, and H. Neuhof. 1986. Increased lung vascular permeability after arachidonic acid and hydrostatic challenge. J. Appl. Physiol. 61:1781-1789.

37. Seeger, W., M. Menger, D. Walmrath, G. Becker, F. Grimminger, and H. Neuhof. 1987. Arachidonic acid lipoxygenase path- ways and increased vascular permeability in isolated rabbit lungs. Am. Rev. Respir. Dis. 136:964-972.

38. Taylor, A. E., and K. A. Gaar. 1969. Calculation of equivalent pore radi of the pulmonary capillary and alveolar membranes. Argent. Angiol. 111:25-40.

39. Seeger, W., D. Walmrath, H. Neuhof, and F. Lutz. 1986. Pulmonary microvascular injury induced by Pseudomonas aeruginosa cytotoxin in isolated rabbit lungs. Infect. Immun. 52:846-852.

40. Schulz, R., and W. Seeger. 1986. Release of leukotrienes into the perfusate of calcium-ionophore stimulated rabbit lungs: influence of 5-lipoxygenase inhibitors. Biochem. Pharmacol. 35:183-193.

40a.Eberspächer, B., F. Hugo, and S. Bhakdi. 1989. Quantitative study of the binding and hemolytic efficiency of Escherichia coli hemolysin. Infect. Immun. 57:983-988.

41. Friberger, P. 1982. A quantitative endotoxin assay utilizing LAL and a chromogenic substrate. Prog. Clin. Biol. Res. 93:195-206.

42. Cavalieri, S. J., and I. S. Snyder. 1982. Cytotoxic activity of partially purified Escherichia coli alpha hemolysin. J. Med. Microbiol. 15:11-21.

43. Patscheke, H., and K. Stegmeier. 1984. Investigations on a selective non-prostanoic thromboxane antagonist, BM 13.177, in human platelets. Thromb. Res. 33:277-288.

44. Stegmeier, K., J. Pill, B. Müller-Beckmann, F. H. Schmidt, E.-C. Witte, H.-P. Wolf, and H. Patscheke. 1984. The pharmacological profile of the thromboxane $A_{2}$ antagonist $B M$ 13.177: a new anti-platelet and anti-thrombotic drug. Thromb. Res. 35:379-395.

45. Seeger, W., Ch. Ernst, D. Walmrath, H. Neuhof, and L. Roka. 1985. Influence of the thromboxane antagonist BM 13.177 on the arachidonic acid-induced increase in pulmonary vascular resistance and permeability in rabbit lungs. Thromb. Res. 40:793-805.

46. Hirshaw, L. B., H. Kuida, R. P. Gilbert, and M. B. Visscher. 1957. Influence of perfusate characteristics on pulmonary vascular response to endotoxine. Am. J. Physiol. 191:292-301.

47. Cintora, I., S. Bessa, G. W. Motsay, and J. W. Borner. 1974. Further studies on endotoxin and alveocapillary permeability. Ann. Surg. 179:372-375.

48. Feuerstein, N., and P. W. Ramwell. 1981. In vivo and in vitro effects on prostaglandin release from rat lung. Br. J. Pharmacol. 73:511-516.

49. Wang, C. G., T. S. Hakim, R. P. Michel, and H. K. Wang. 1985. Segmental pulmonary vascular resistance in progressive hydrostatic and permeability edema. J. Appl. Physiol. 59:242-247.

50. Raj, J. U., R. D. Bland, and S. J. Lai-Fook. 1986. Microvascular pressures measured by micropipettes in isolated edematous rabbit lungs. J. Appl. Physiol. 60:539-545.

51. Michel, R. P., L. Zocchi, A. Rossi, G. A. Cardinal, Y. PloySong-Sang, R. S. Poulsen, J. Milic-Emili, and N. C. Staub. 1987. Does interstitial lung edema compress airways and arteries? A morphometric study. J. Appl. Physiol. 62:108-115.

52. Seeger, W., and N. Suttorp. 1987. Role of membrane lipids in the pulmonary vascular abnormalities caused by bacterial toxins. Am. Rev. Respir. Dis. 136:462-466.

53. Füssle, R., S. Bhakdi, A. Sziegoleit, J. Tranum-Jensen, T. Kranz, and H. J. Wellensiek. 1981. On the mechanisms of membrane damage by staphylococcus aureus alpha-toxin. J. Cell Biol. 91:83-94.

54. Bhakdi, S., and J. Tranum-Jensen. 1987. Damage to mammalian cells by proteins that form transmembrane pores. Rev. Physiol. Biochem. Exp. Pharmacol. 107:148-223.

55. Suttorp, N., W. Seeger, E. Dewein, S. Bhakdi, and L. Roka. 1985. Staphylococcal alpha-toxin-induced $\mathrm{PGI}_{2}$ production in endothelial cells: role of calcium. Am. J. Physiol. 248:C127-C134.

56. Suttorp, N., W. Seeger, J. Zucker-Reimann, L. Roka, and S. Bhakdi. 1987. Mechanism of leukotriene generation in polymorphonuclear leukocytes by staphylococcal alpha-toxin. Infect. Immun. 55:104-110. 